\title{
EL ACTOR ALONSO DE OLMEDO: UN ENTREMESISTA EN LA ÓRBITA DE CALDERÓN
}

\author{
Francisco Domínguez Matito \\ Departamento de Filologías Hispánica y Clásicas \\ Universidad de La Rioja \\ C/ San José de Calasanz, 33 \\ 26004 Logroño, La Rioja. España
}

[Anuario calderoniano (ISSN: 1888-8046), 7, 2014, pp. 129-147]

A estas alturas, es verdad que el antes denominado, con rotulación despectiva, "teatro menor», cuenta ya con una más que considerable bibliografia, que hace justicia a ese inmenso caudal que don Emilio Cotarelo llamaba «fugaces destellos de la radiante y majestuosa Talía española» ${ }^{1}$ No era para menos, después de haber documentado el mismo Cotarelo la magnitud y la importancia del arsenal en el desarrollo de la fiesta teatral barroca ${ }^{2}$, y de que fuese tan luminosamente seña-

1 Cotarelo y Mori, 1911, I, p. I.

2 Cotarelo y Mori, 1904. Es justo añadir a la labor del bibliógrafo e historiador asturiano la meritoria e infatigable investigación desarrollada por los hispanistas británicos Shergold y Varey en su colección documental «Fuentes para la Historia del Teatro en España, donde aportan infinidad de testimonios sobre representaciones de entremeses. 
lado el itinerario por los clásicos estudios de Eugenio Asensio ${ }^{3}$ y Hannah Bergman ${ }^{4}$. Pero algunos años habrían de pasar aún para que se produjera un cambio cuantitativo en la atención al ahora distinguido, en valoración más exacta, con el marbete de «teatro breve», que se nos muestra ya sin complejos y en su justo lugar.

En un artículo de hace veinte años García Valdés situaba en la década de los años ochenta el punto de inflexión en el conocimiento, estudio y edición de estas piezas, recordando el impulso que a los estudios del «teatro breve» - por entonces todavía «teatro menor»dieron dos encuentros celebrados sobre el tema, uno en la Casa de Velázquez (1983) y otro en las Jornadas de Teatro Clásico de Almagro de $1987^{6}$. García Valdés concluía su aludido trabajo constatando que

el teatro menor clásico no está muerto ni para los estudiosos teóricos ni para la escena. Al contrario, en los últimos años se ha dado un paso de gigante en su estudio y recuperación. Pero no hay que olvidar que es mucho lo que queda por hacer ${ }^{7}$.

De ese «paso de gigante» venía dando cuenta, ya por entonces, la recopilación bibliográfica de Agustín de la Granja ${ }^{8}$. Hoy, las bibliografias del mismo De la Granja con Lobato ${ }^{9}$, o de Madroña $1^{10}$, ofrecen un panorama casi inabarcable sobre este género de forma tan proteica, que cuenta también con la reciente y voluminosa obra historiográfica dirigida por Huerta ${ }^{11}$. Por todas ellas circula el rey del «teatro breve» - el entremés-, pero también las loas, las mojigangas, las jácaras, los bailes, etc., analizados desde múltiples puntos de vista. Entre los autores más insistentemente estudiados y editados, como no podía ser de otra manera, están Cervantes, Quevedo, Calderón, Moreto y,

${ }^{3}$ Asensio, 1965.

4 Bergman, 1965.

${ }^{5}$ El teatro menor en España a partir del siglo XVI, 1983.

${ }^{6}$ Ver García Lorenzo, 1988.

${ }^{7}$ Ver García Valdés, 1993, pp. 121-122.

${ }^{8}$ De la Granja, 1987, pp. 227-246, y 1990, pp. 113-124.

${ }^{9}$ De la Granja y Lobato, 1999.

${ }_{10}$ Madroñal, 2004, pp. 455-474.

${ }^{11}$ Huerta Calvo, 2008. Para un paseo por los «caminos de la crítica» de hace ya una decena de años, pero que no ha perdido vigencia, ver también Huerta Calvo, 2001, pp. 193-200. 
por supuesto, Quiñones de Benavente ${ }^{12}$; a gran distancia, Bances Candamo $^{13}$, y Vélez, Salas Barbadillo, Quirós, Diamante, Lanini, Zabaleta, Avellaneda, etc., autores que nos hizo accesibles el selecto «ramillete» ofrecido por Bergman ${ }^{14}$.

Si me he detenido en este sucinto memorándum es para señalar que, en cierto sentido, ocurre con respecto al «teatro breve» algo parecido a lo que sucede con el teatro barroco en general, donde Lope, Calderón, Tirso ocupan casi toda la escena, y solo recientemente están asomando "desde el paño», con mayor o menor medida de cuerpo, autores como Moreto, Rojas, Mira de Amescua,Vélez de Guevara, Cubillo de Aragón, etc. Y es aquí cuando quiero recuperar la reflexión final de las palabras de García Valdés, anteriormente citadas, sobre «lo mucho que queda por hacer», para traerla hacia otros «humildes» autores que, entre las tablas y el papel, contribuyeron al éxito no ya solo del «teatro breve» sino del espectáculo de la "comedia» en general y de muchas «funciones» teatrales en particular. Me refiero a los «autores de comedias» o actores que, por vocación o necesidad, decidieron ejercer también de dramaturgos. Al fin y al cabo, la vinculación de algunos actores con el género del entremés iba más allá de una relación puramente — digamos— «actoral» u ocasional, para convertirse en extensiones de su propia personalidad, pues sabido es que algunos poetas dramáticos concibieron piezas expresamente para - $\mathrm{o}$ adaptadas a - las características profesionales o personales de determinados actores; de modo que muchos entremeses (o su puesta en escena) estaban identificados con nombres concretos de la farándula y servían tanto de reclamo comercial como para el exclusivo lucimiento del actor. Recordemos, por ejemplo, la relación abierta que hace Rojas Villandrando en El viaje entretenido:

De los farsantes que han hecho farsas, loas, bailes, letras: son Alonso de Morales, Grajales, Zorita, Mesa, Sánchez, Ríos, Avendaño,

${ }^{12}$ Ver, por ejemplo, el caso de la Jocoseria de Quiñones de Benavente (ed. Arellano, Escudero, Madroñal, 2001).

13 Ver Arellano, Spang y Pinillos, 1994.

14 Bergman, 1985. 


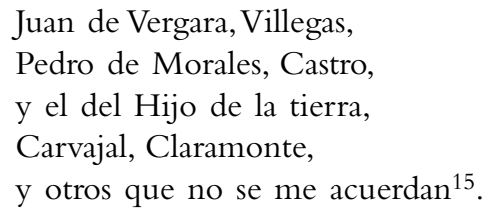

A esta somera nómina testimonial de actores-dramaturgos podrían añadirse otros, de los que Rojas, claro, no tenía motivos para acordarse, como Matías de Castro "Alcaparrilla», autor de sainetes, bailes, entremeses, mojigangas y jácaras; Antonio Escamilla, que con la colaboración de Manuel Vallejo compuso bailes y entremeses; el mismo Manuel Vallejo, quizá autor con Escamilla de las piezas breves que acompañaron la puesta en escena de El hijo del Sol, Faetón; Bernardo López del Campo, autor de bailes y mojigangas, etc. ${ }^{16}$.

Pues bien, en este catálogo de actores metidos a dramaturgos se encuentra el famoso Alonso Pedro de Olmedo Tofiño, conocido en el mundo de las tablas por el apodo de "el Mozo». De apellido («Olmedo») muy corriente en la farándula, él mismo pertenecía a una estirpe de cómicos. Hijo del autor Alonso de Olmedo Tofiño y Agüero y de la actriz Jerónima de Omeño — de ahí que en alguna bibliografia aparezca como Alonso de Olmedo y Omeño- ${ }^{17}$, compartió dedicación al teatro con sus hermanas Jerónima y María, esposas respectivamente de los actores Juan Navarro Oliver y Juan Pérez de Tapia; Juana (casada con el bordador Francisco de Salas); su hermano Vicente (marido de Francisca de Rojas y Zorrilla, apodada «Bezón» o «la Bezona»).

El nacimiento de Alonso de Olmedo en Zaragoza está relacionado con las vicisitudes de la vida amorosa de su padre - Tofiño y Agüero-, natural de Talavera de la Reina, donde era paje del conde de Oropesa. El joven paje, según lo que hoy se calificaría como una «leyenda urbana», habría ingresado en la profesión cómica al haberse enamorado de una actriz — ¿quizá Luisa de Robles? - al paso de su compañía — ¿la de Diego Vallejo? — por Talavera. Los dimes y diretes del proceloso mundo de los comediantes hicieron correr la especie de que el enamorado Olmedo, no pudiendo en principio conseguir a la

\footnotetext{
15 Rojas Villandrando, El viaje entretenido, pp. 157-158.

${ }^{16}$ Ver Urzáiz Tortajada, 2002.

${ }^{17}$ Ver Urzáiz Tortajada, 2002, vol. II, pp. 488-489.
} 
actriz por su condición de casada, recibió un golpe favorable de la fortuna cuando la embarcación que conducía al marido de su amada a Vélez-Málaga para ajustar unas representaciones, fue abordada por piratas berberiscos en cuyas manos desapareció. Olmedo pudo casarse entonces con la supuesta viuda, con la cual vivió dos o tres años. Pero, vuelta ahora la rueda de la fortuna en su contra, un día en que estaba comiendo con su mujer en Granada, se presentó el redivivo marido preguntando por él, y Olmedo, al reconocerlo, dándose de repente por divorciado, se despidió de ella con todo su sentimiento. De toda esta hojarasca más o menos fabulosa, lo más verosímilmente documentado es, en efecto, la relación del viejo Olmedo con la actriz Luisa de Robles, relación que duró varios años y que, por algunas coincidencias con las susodichas circunstancias, pudo dar lugar a tergiversaciones. Por otra parte, parece que el bueno de Olmedo debió de estar casado con la actriz Margarita Humana antes de trasladarse a Zaragoza, y allí es donde contrajo matrimonio con Jerónima de Omeño, hija del mayordomo del conde de Sástago. Al parecer, en la capital aragonesa se encontraba cuando dejó la actividad cómica y donde en 1647 obtuvo de Felipe IV el reconocimiento para él y sus descendientes de la condición de hijosdalgo e infanzones de Aragón.

Residiendo sus padres en Zaragoza nació, pues, nuestro Alonso Pedro de Olmedo Tofiño, probablemente en 1626. Por la carta ejecutoria de hidalguía otorgada por el Consejo en 1646 sabemos que, antes de dedicarse al teatro, había sido "ordenado de grados y corona y graduado de bachiller en cánones por la Universidad de Salamanca». Casado con la actriz María Antonia de León, nacida en Vélez-Málaga, hacia 1652, tuvo la mala fortuna de que don Juan Gaspar Enríquez de Cabrera, almirante de Castilla, se enamorara de su mujer, a quien secuestró, de tal manera que los esposos nunca más volvieron a verse. Viudo de facto y a la fuerza, tuvo tres hijos naturales con la actriz María de Anaya (Gaspar de Olmedo, Alonso Armando y María de Anaya) y otro hijo natural con la también actriz Manuela de Escamilla (Alonso Anacleto Jerónimo de Olmedo). Dos de ellos, Gaspar y Alonso Anacleto siguieron el oficio de su padre.

El autor (o autores) de la Genealogía de los comediantes de España reserva muy buena opinión para nuestro actor Alonso de Olmedo, a quien considera «hombre de muy buen juicio y buena conversación y de muy buenos procedimientos, cortesano y atento». De acuerdo 
con las noticias de que disponemos, debió de comenzar su carrera hacia 1639 en la propia compañía de su padre, y la desarrolló posteriormente en las de los célebres autores Pedro de la Rosa, Mariana Vaca, Diego Osorio, Juan Pérez de Tapia, Simón Aguado y Juan de la Calle. Formando parte de la compañía conjunta de Antonio Escamilla y Manuel Vallejo, murió Alonso de Olmedo durante la primavera o principios del verano de 1682 en Alicante, donde "se le hizo un entierro muy ostentoso asistiendo el cabildo eclesiástico de los canónigos» ${ }^{18}$. Este último detalle da fe de la gran reputación que había alcanzado tanto en los teatros populares y fiestas de Corpus de Andalucía, Madrid, Valencia,Valladolid, Toledo, etc., como en los salones de palacio, ya en el salón dorado del Alcázar o en el coliseo del Buen Retiro ${ }^{19}$. Así lo recoge la Genealogía de comediantes al manifestar que «hizo galanes en las compañías de Madrid muchos años con grandísimo aplauso y tanto que compitió con Sebastián de Prado, y divididos en la corte los pareceres y sentires se redujo el aplauso de entrambos [sic] opiniones» ${ }^{20}$.

Algunos de los más importantes autores dramáticos, en fin, lo festejaron también, como, por ejemplo, Agustín Moreto en el entremés La loa de Juan Rana (vv. 152-171), en la escena en la que el afamado gracioso acepta el desafio para imitar a otros actores importantes:

RANA

Digo que Escamilla soy mas por que verdad os diga, yo entre mí pensaba que era así un tantico Escamilla.

Mas ¿cómo he de ser Olmedo con la cara de un Macías, bigotillo a la francesa, planta de retrato, y vista la capita a la jineta y con la habla de almíbar? Eso no.

18 Para los datos anteriores, ver Pellicer, 1804, pp. 17 y 18; Sánchez Arjona, 1898, p. 339; Cotarelo y Mori, 1908, p. 210; 1911, I, p. CIX, y 1916, pp. 179-180; Bergman, 1965, pp. 512-514; González Hernández, 1986, p. 192; Lobato, 1999, pp. 79-111; Genealogía..., pp. 89, 132, 139, 141, 155-156, 161, 190, 306-307, 361, 457, 460, 479481, 511, 561-562. Ver Ferrer Valls, 2008.

${ }^{19}$ Ver Huerta Calvo, 2001, pp. 44 y 178.

20 Genealogía..., p. 161. 


$\begin{aligned} & {[\ldots] } \\ & \text { ¡No es posible! ¡Ave María! } \\ & \text { El mismo Olmedo parezco } \\ & \text { cortada la cara. } \\ & {[\ldots] } \\ & ¡ \text { Qué galán soy! } \\ & \text { ¡Bien pueden darme una higa! } \\ \text { MúsicA } & \text { Ya en Olmedo, señores, } \\ & \text { Rana se ha vuelto, } \\ & \text { el galán de la loa, } \\ & \text { la flor de Olmedo }{ }^{21} .\end{aligned}$

$\mathrm{Al}$ parecer, el prestigio de Alonso de Olmedo estaba sustentado por su brillante ejecutoria en los papeles de galán, en cuyo repertorio se contaba La presumida y la hermosa de Fernando de Zárate, Los celos hacen estrellas de Vélez de Guevara, El celoso extremeño de Cervantes, Entre bobos anda el juego de Rojas Zorrilla, y las obras de Calderón Hado y divisa de Leonido y de Marfisa, El hijo del sol, Faetón, Psiquis y Cupido, La púrpura de la rosa, Los tres mayores prodigios, Fieras afemina amor, etc. ${ }^{22}$.

Sin embargo, la faceta de su personalidad que nos interesa aquí especialmente es la de escritor dramático. Sobre este aspecto manifiesta la Genealogía de los comediantes que "escribió con gran acierto y discreción algunos bailes y sainetes y muy buenas coplas así para palacio como para la villa» ${ }^{23}$.Y, en efecto, diversas bibliografias del teatro áureo le atribuyen una obra nada despreciable, si bien se muestran contradictorias o vacilantes en la adscripción genérica de algunas de sus composiciones ${ }^{24}$. Por el momento, parece seguro que escribió la segunda jornada de Antíoco y Seleuco, comedia burlesca basada en la homónima de Moreto, en colaboración con Jusepe Rojo y quizá con Matos

${ }^{21}$ Moreto, La loa de Juan Rana, en Lobato, II, 2003, pp. 621-622. Recogido también en Cotarelo, 1911, I, p. CIX.

${ }^{22}$ Ver Pérez Pastor, 1914, p. 197; Cotarelo y Mori, 1916, p. 32; Vélez de Guevara, Los celos hacen estrellas, p. XLIX;Varey y Shergold, 1973, p. 240; Shergold y Varey, 1982, pp. 72, 75, 80-82, 90, 104, 108, 109, 238 y 239; Greer y Varey, 1997, pp. 39, 97 y 101; Urzáiz Tortajada, 2002, pp. 488-489.

23 Genealogía..., p. 161, y Pellicer, 1804, pp. 17-18.

24 Ver Barrera y Leirado, 1860, pp. 286-287; Díaz de Escovar, 1909; Cotarelo, 1911, I, pp. CIX-CX; Muñoz, 1953, pp. 95-99; Varey y Shergold, 1970, p. XCII, y 1989, p. 115. 
Fragoso; una serie de bailes, algunos de ellos publicados en diversas colecciones (El Lanturulú o Atención pido a todos ${ }^{25}$; La niña hermosa ${ }^{26}$ ) y otros transmitidos y conservados en copias manuscritas (La abejuela; Las arias $^{27}$; Menga y Bras, El retrato ${ }^{28}$. Tenemos constancia de que algunos de sus bailes fueron representados en palacio, junto con obras de Calderón: son los casos de La gaita gallega, puesto en escena el 22 de diciembre de 1679 con El hijo del Sol, Faetón; de Las flores, durante el carnaval de 1680, junto con Hado y divisa de Leonido y de Marfisa; de Los estudiantes, representado el 18 de enero de 1680 junto con $\mathrm{La}$ púrpura de la rosa ${ }^{29}$. Debidos a su pluma se conservan también, hasta donde sabemos, los siguientes entremeses: Píramo y Tisbe, Las locas caseras, La dama toro y El sacristán Chinchilla.

El más interesante de estos entremeses de Olmedo es, sin duda, Píramo y Tisbe, transmitido en una copia manuscrita del siglo XVIII, a la que le falta una última hoja con el desenlace ${ }^{30}$. Estructurado en Primera y segunda parte, la pieza de Olmedo se basa en la trágica historia de los dos amantes babilonios, recogida por Ovidio en sus Metamorfosis y de gran circulación en toda la literatura europea. En España, Gregorio Silvestre, Cristóbal de Castillejo, Jorge de Montema-

25 Arcadia de entremeses..., 1691. La autoría de este baile es cuestionada por Lobato, 2003, I, p. 157.

26 Floresta de entremeses..., 1691.

${ }^{27}$ Aunque atribuido a Olmedo, Lobato (2003, I, p. 157) descarta su autoría.

28 El baile Dos áspides trae Jacinta, atribuido a Alonso de Olmedo en el Vergel de entremeses, y conceptos del donayre..., 1675, es, en realidad, de Francisco Monteser. Hay contradicción entre las diversas bibliografias sobre si pertenecen al género del baile o del entremés Bernarda y Pascual (o Sainete para la comedia de Los sucesos de tres horas o Si no ha de tener alivio), conservado en varias colecciones manuscritas del XVII y XVIII, y Títulos de comedias, impreso en la colección Rasgos del ocio en diferentes bailes, entremeses y loas... de 1664. Ver Cotarelo, 1911, I, pp. CX, Urzáiz Tortajada, 2002, II, p. 489, y Lobato, I, 2003, p. 157.

${ }^{29}$ Ver Urzáiz Tortajada, 2002, II, p. 489. Según Cotarelo (1911, I, p. CXCIX), el baile de los Títulos de comedias fue estrenado en 1662 ante Felipe IV, y el Sainete de Alonso de Olmedo para la comedia de Los sucesos de tres horas fue compuesto con motivo de la fiesta de cumpleaños de la reina en 1664.

${ }^{30}$ El texto de Píramo y Tisbe, que forma parte de una colección de entremeses y bailes cuyo ejemplar se encuentra en la Biblioteca Nacional de Madrid (Sign. Mss/14851, fols. 218-224), ha sido editado por Senabre, 1981, pp. 235-244. Una copia decimonónica del entremés se encuentra en el Instituto del Teatro de Barcelona (Sign. 46569). Ver Simón Palmer, 1977, p. 47. 
yor, Góngora, habían contribuido a su difusión entre el público culto $^{31}$, pero sin duda toda clase de gentes estaba familiarizada con el mito, a juzgar por el testimonio de Cervantes en el Entremés del vizcaíno fingido:

BRíGIDA: Esta, Cristina amiga, no solo es ventura, sino venturón llovido. ¡Desdichada de mí, y qué desgraciada que soy, que nunca topo quien me dé un jarro de agua sin que me cueste mi trabajo primero! Solo me encontré el otro día en la calle a un poeta, que de bonísima voluntad y con mucha cortesía me dio un soneto de la historia de Píramo y Tisbe, y me ofreció trecientos en mi alabanza ${ }^{32}$.

El mismo Góngora, al comienzo de su Fábula de Píramo y Tisbe (1618), declaraba la universalización de la leyenda y el deseo de «popular aplauso» por ponerla «en las orejas del vulgo» (vv. 14-15) ${ }^{33}$. La historia de Píramo y Tisbe, por otra parte, era frecuentada alusión en gran cantidad de comedias: así, por ejemplo, en La dama duende de Calderón; La fortuna merecida de Moreto; Los amantes de Teruel y Por el sótano y el torno de Tirso; El anzuelo de Fenisa, Los bandos de Sena, La viuda valenciana de Lope, etc., etc. De modo que cuando Alonso de Olmedo decidió escribir para el teatro su entremés de Píramo y Tisbe, sabía que contaba con una recepción ya suficientemente preparada por parte de los espectadores de los corrales de comedias. Solo así era posible darle un tratamiento burlesco a la desgraciada historia de los dos enamorados de Babilonia; y ese es, precisamente, el interés de esta obrita de Olmedo: su carácter paródico, bien contextualizado en el «itinerario del entremés», pero también en el creciente desarrollo de la comedia burlesca y, particularmente, en el tratamiento irónico que el mito comenzó a tener ya desde la versión del romance gongorino o los Donaires del Parnaso (1624) de Castillo Solórzano ${ }^{34}$. Como ya observaba Cotarelo, el entremés de Olmedo «más bien parece una comedia burlesca en un acto, donde los amores de Píramo y Tisbe son

${ }^{31}$ Ver Cossío, 1998.

32 Cervantes, Entremés del Vizcaíno fingido, p. 116.

33 Góngora, Romances, pp. 362-420.

34 Ver Cossío, 1998, II, pp. 90-92. Para los Donaires del Parnaso de Castillo Solórzano, ver la edición de López Gutiérrez, 2005. 
tratados en parodia ${ }^{35}$, y hay que enmarcarlo, pues, en esa tradición burlesca de enfocar el mito que de manera definitiva consagró para el teatro Pedro Rosete en su Comedia famosa de Píramo y Tisbe (1668).

La composición de la pieza responde desde el principio a su pretendido carácter burlesco, y su desarrollo, como veremos también en el resto de los entremeses, revela la intención «espectacular» propia de un autor muy consciente de los gustos del público y de la funcionalidad del género en el conjunto de la fiesta teatral. Los personajes principales se presentan a sí mismos de manera grotesca: Píramo, como un gato que acecha a Tisbe por desvanes y zaquizamíes; Tisbe, buscando a Píramo por vericuetos y andurriales; la pared, que en el mito separaba y unía al mismo tiempo a los amantes, personificada en la figura de una alcahueta. Cuando un Píramo de modales y lenguaje algo atrevidos propone la huida a la muchacha, Tisbe reacciona primero con los remilgos de una doncella deshonrada e inmediatamente después pícara y regocijada por escapar de los sermones de su padre, de las asechanzas de las criadas y de los chismes de su tía. La pared «alcahueta» les facilita la huida prestándoles disfraces equívocos — un sombrero para Tisbe y un moño para Píramo- que preludian la divertida escena en la que el padre de Tisbe y la madre de Píramo sorprenden a los amantes en su intento de fuga, confundiéndolos por los disfraces. Pero aprovechando esta confusión y la oscuridad, estos logran evadirse, al tiempo que "salen dos criados, cada uno con su luz, lo más ridículos que puedan». Así concluye la primera parte de la obrita.

Con los mismos ingredientes de parodia, la segunda parte desarrolla el episodio de la fuente y el trágico desenlace de los dos enamorados. Aquí Olmedo recurre al ingenio de sustituir el león (o leona) de la leyenda por la figura de una «dueña» malvada que pretende corregir la indecente conducta de la muchacha. Después de una escena de insultos y forcejeos de las dos mujeres, al hilo del desarrollo de la trama del mito, la dueña al fin muerde la toca de Tisbe y la ensangrienta. El delirio paródico alcanza su cumbre cuando Píramo, al llegar al lugar y descubrir la toca ensangrentada de Tisbe, finge darse muerte con un puñal empapado en sangre de pollo conservada en una esponja que ya tenía prevenida. Se acerca entonces una Tisbe burlona a la escena y ve al joven «bañado en su sangre, o en otra, / que yo en

35 Cotarelo y Mori, 1911, p. CX. 
si es suya o no, no me meto»; comprueba que Píramo "aún no ha expirado pues abre los ojos", y es que, como el mismo Píramo confiesa abundando en la farsa, los abre y los cierra a su antojo. La caricaturesca escena concluye con un irónico diálogo entre los dos amantes y con el chusco comentario de Píramo ( $«$ Tisbe es y vive! / Si yo me matara / muy buena hacienda hubiéramos hecho!») que adelanta sin duda un lieto fine contrario al trágico final de la leyenda. Pero justamente ahí es donde se interrumpe el manuscrito. Ya solo con estos motivos en la versión paródica de la trágica leyenda tenía Olmedo materia suficiente para una caricatura que sirviera de regocijo a los espectadores, pero, según su estilo, aún adornó el desarrollo de la acción entremezclando partes representadas y recitativas con pasajes cantados en seguidillas arromanzadas y un baile de chacona con corro y cruzado, lo que situaba su Píramo y Tisbe en la lábil frontera genérica del entremés cantado y el baile entremesado.

El resto de los entremeses de Olmedo - Las locas caseras, La dama toro y El sacristán Chinchilla - se encuentran en versiones manuscritas y aparecieron impresas primeramente en una colección titulada Flores del Parnaso $(1708)^{36}$ y después circularon en ediciones sueltas a lo largo del XviII ${ }^{37}$. En todos ellos el actor-dramaturgo se sitúa dentro de la tradición del género, es decir, benaventina, con temas y motivos populares, personajes más o menos estrafalarios y situaciones grotescas ${ }^{38}$.

Las locas $\operatorname{caseras}^{39}$ se inscribe dentro del abundante conjunto de entremeses que se dirigen a criticar usos sociales, en este caso, la vanidad de las mujeres por su deseo de aparentar lo que no son. La intención crítico-burlesca de la pieza, así como el tema (o subgénero) al que

36 Flores de el Parnaso, cogidas para recreo del entendimiento, por los mejores ingenios de España..., 1708. Integran esta colección una loa y varios entremeses, bailes y mojigangas pertenecientes a diversos autores (Antonio Zamora, Bances Candamo, Vicente Suárez, Francisco Tejera) y, entre ellos, el Entremés del dragoncillo, la Mojiganga de la negra y la Mojiganga de la muerte de Calderón de la Barca. Los entremeses de Olmedo están entre las pp. 80-109. Existe un ejemplar de esta edición en la Biblioteca Nacional de España, Sign. T/9025.

${ }^{37}$ Ver Cotarelo, 1911, I, pp. CCXXXII y CIX-CX, y Urzáiz Tortajada, 2002, pp. 488-489.

${ }^{38}$ Ver Cotarelo, 1911, pp. CXLVIII-CLV; Bergman, 1965, pp. 138-157.

39 Flores de el Parnaso, pp. 80-89. 
pertenece, lo declaran el gracioso y el personaje principal en las seguidillas arromanzadas con que concluye la acción:

$\begin{array}{ll}\text { Gracioso } & \text { Esta visita, niña, } \\ & \text { por lo que veo, } \\ & \text { como otras son de chistes, } \\ & \text { es de sujetos. } \\ \text { María } & \text { Que eso es decirnos locas, } \\ & \text { yo no lo ignoro; } \\ & \text { los hombres nos ensenan } \\ & \text { a lo que somos. }\end{array}$

El argumento, de gran simplicidad, basado en una escena cotidiana, reúne a seis mujeres en un estrado casero para charlar en torno a una taza de chocolate. Tres de ellas rivalizan en ostentación de grandeza y otras tres les sirven de comparsa. La anfitriona presume de una posición social ficticia; otra, de tener encumbrados pretendientes entre los cuales no sabe a quién elegir; y la última, de estar emparentada con los mayores títulos de la nobleza. El presuntuoso diálogo de la tertulia femenina se ve continuamente interrumpido por una criada impertinente, que aparece para quejarse de la escasez del «chocolate de Guajaca», y los gritos y llantos del hijo de la anfitriona. Finalmente, el niño, "que lo ha de hacer un hombre muy ridículo», irrumpe en la escena haciendo monadas y sucede un baile en el que participa el mismo niño. Entre la algarabía y tanto barullo sobre el tablado sale la criada con el chocolate, tropieza, cae, y la bandeja vuela por los aires, derramándose finalmente el chocolate sobre todos los presentes y provocando la caída del niño. Termina el entremés con los reproches a la torpe criada y con las seguidillas citadas más arriba ${ }^{40}$. El breve cuadro costumbrista retrata con mucha gracia el habla popular y picante de las mujeres, que se expresan en silvas de variedad combinatoria. A su dinámica contribuye no solo el agitado diálogo femenino continuamente interrumpido por las circunstancias, sino también la intercalación de pasajes cantados, como el que protagoniza una de las mujeres - Ignacia - que entona el viejo romance de

${ }^{40}$ Ver Cotarelo, 1911, I, pp. CIX-CX, y Huerta Calvo, 2008, pp. 430-431. 
Inocente mariposa

que te arrojas a las llamas, si no has de imitar al Fénix, dime, ¿para qué te abrasas? ${ }^{41}$

El elenco de La dama toro ${ }^{42}$ está constituido por seis personajes: Comisario, Mosquera, Malaguilla, Simón y dos hombres. Esto hace pensar que Alonso de Olmedo, siguiendo una costumbre muy propia de los autores de entremeses, escribió esta pieza para que fuera representada por sus compañeros de farándula, pues no parece que puedan corresponder a otros los personajes del elenco Manuel Mosquera, Juan de Malaguilla (Mendieta) y Simón Aguado (apodado "el joven»), estos dos últimos especializados en los papeles de graciosos ${ }^{43}$. Simón (Aguado) representa aquí a un galán enamorado a punto de quitarse la vida, desesperado por la persecución de un comisario de amancebamientos. Como resulta que en la villa no hay otros enamorados que Simón y su Gracia, el comisario atropella la casa de Simón de continuo con el objetivo de sorprender a los amantes. Los amigos de Simón - Malaguilla con la complicidad de Mosquera - ingenian entonces una estratagema para corregir tales desafueros y aliviar a su amigo de la angustia que padece: encerrar un toro en una de las habitaciones de la casa de Simón, de tal manera que cuando el comisario vaya a sorprender a los amantes, se encuentre con el toro; de ahí el título del entremés. Así que el amigo del galán se encuentra con el comisario, "que es el gracioso, de villano, con vara de alcalde», y «lo lleva corriendo por el tablado", fingiendo delatar el encuentro de los dos amantes. Preso de excitación, el comisario allana la morada y ordena a sus ayudantes que registren toda la casa. Solo un aposento se encuentra cerrado con llave, y es donde los cómplices de la burla han encerrado un toro. De nada sirven los avisos y prevenciones que Simón hace al comisario. Este, convencido como está de que en dicho aposento se encuentra oculta la dama, manda abrir la puerta y «sale un toro y embiste con todos». Con esta escena hilarante, casi una charlotada, sin que la

${ }^{41}$ Ver Romancero general, p. 435, y Lambea Castro y Josa, 2009, pp. 397-448.

42 Flores de el Parnaso, pp. 90-99. Ver Cotarelo, 1911, I, p. CX, y Huerta Calvo, 2008, pp. 430-431.

${ }^{43}$ Ver Ferrer Valls, 2008. Precisamente, en uno de los diálogos entre Mosquera y Simón, aquel se refiere a Malaguilla por su nombre de pila, Juan. 
sangre llegue al río, concluye el entremés, al que debía de seguir un baile, según anuncia Mosquera en la despedida:

Mosquera
venga, que hacia su vacada
y sin haber peligrado
ninguno entre tantas vueltas,
a celebrar con un baile
vengo la burla.

Si en La dama toro Olmedo acude al socorrido personaje entremesil del alcalde villano -obsérvese que al comisario se le hace aparecer con vara de alcalde y representa el papel del gracioso-, blanco y objeto de burlas, en El sacristán Chinchilla ${ }^{44}$ confia nuevamente el protagonismo de su entremés a uno de los tipos más característicos del género ${ }^{45}$. El sacristán "Chinchilla», en efecto, comparte con muchos otros sacristanes entremesiles sus rasgos burlescos. Cuando sale a escena se le presenta «muy desandrajado con sotana»; uno de los personajes lo ridiculiza como «ese sacristán Chinchilla / tan bullicioso y pequeño, / que siendo alma en la viveza, / en lo aparente no es cuerpo»; y otro lo caricaturiza como "lagartija con sotana» y «escarabajillo con bonete». Siguiendo el estereotipo, se trata de un «enamorado» con pretensiones de poeta, que corteja a Casilda, mujer equívoca, con una encendida silva:

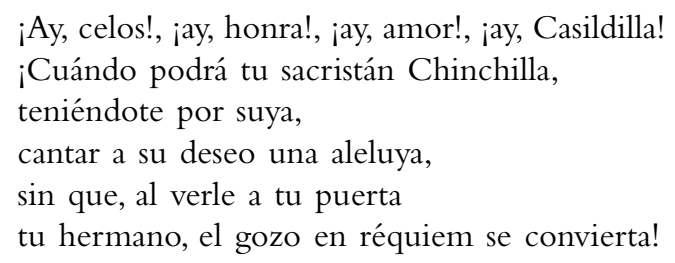

Pero no solo interviene en este entremés el «tipo» del sacristán, también otros personajes propios del género, como un bodegonero, un alcalde, un escribano y un hermano celoso. De acuerdo con las convenciones, si el sacristán enamorado introduce en su habla algún

44 Flores de el Parnaso, pp. 100-109.

${ }^{45}$ Ver Bergman, 1965, pp. 128-131. 
latinajo, también el ventero, ladrón y falsario, aparece caracterizado por su jerga:

\author{
¿Qui venga sin su capa y sin sombrero? \\ Por el amor, monsiur bodegonero, \\ buscando li beldad de Casildilla, \\ dejando de guisar la albondiguilla, \\ el gigote estofado y les pucheros \\ con que robando estoy lus pasajerus, \\ mas todo lo merese li muchacha. \\ ¡Válgati dos mil diablis li borracha!
}

El asunto es que el hermano de Casilda, que tiene comprometido el matrimonio de su hermana con el alcalde, quiere vengarse del importuno sacristán, que arteramente logra cortejar cada noche a Casilda burlando la vigilancia de su hermano. Para vengarse de la burla, el hermano de Casilda contrata a dos matones que escarmienten al impertinente galán cuando lo sorprendan in fraganti. Con el mismo objetivo de darle su merecido al sacristán competidor, el alcalde enamorado de Casilda dispone una ronda con el alguacil y el escribano. Puestos todos al acecho, aparece el sacristán con una escalera para subir a la habitación de su enamorada, y a partir de ese momento se sucede un gran enredo cómico, aprovechando la oscuridad de la noche, en el que el bodegonero se interpone entre el sacristán y Casilda, la ronda agarra al sacristán por la faja para hacerlo caer, la escalera se atraviesa cuando acuden los demás y todos los representantes terminan magullados por los atropellos y a palos entre ellos ${ }^{46}$.

De los entremeses de Olmedo, Píramo y Tisbe, como apunté más arriba, es, desde luego, el de mayor inspiración y densidad dramáticas, pero las otras tres piececitas (alrededor de 250 versos cada una) en las que nos hemos detenido resultan deliciosas. La combinación del costumbrismo con la ridiculización de tipos y usos sociales que se inscriben entre la convención teatral y literaria, convierten a los entremeses de Olmedo en un testimonio de la realidad - y de la realidad del espectáculo teatral- y nos revelan a un dramaturgo bien consciente de las claves que presidían los gustos del público. Alonso de Olmedo, por su práctica profesional, sabía de qué se trataba, y en sus

${ }^{46}$ Ver Cotarelo, 1911, I, p. CX, y Huerta Calvo, 2008, pp. 430-431. 
breves entremeses, siempre a medio camino entre el texto, el espectáculo y las convenciones genéricas, trataba de satisfacer los deseos del espectador. De ahí que la gracia de los diálogos, expresados en silvas y romances que el dramaturgo maneja con soltura, se alternen con esa especie de gags en que consisten sus escenas de enredo y alboroto, y con el ritmo de canciones y bailes (en seguidillas, romances cantados), todo ello constituyendo un cuadro de diversión que debía de provocar la excitación y el regocijo del patio de comedias o de los salones de palacio. De que Olmedo estaba muy atento a conseguir los efectos cómico-espectaculares que pretendía dan cuenta precisamente las abundantes acotaciones escénicas, que no se limitan a señalar las entradas y salidas de los personajes, sino también las puntuales condiciones de la escenificación. Véanse estas, por ejemplo: «Saca el chocolate la criada y topa con el niño y cae» (Las locas caseras); "Sale Malaguilla, cogiendo al comisario de la mano, lo lleva corriendo por el tablado», «Sale un toro y embiste con todos» (La dama toro); «El bodegonero ha de estar en medio de los dos, de suerte que ella piense que habla con Chinchilla, y haga el bodegonero lo que había de hacer Chinchilla», "Súbese en la escalera y sale la Justicia con linterna», «Ha de llevar un ceñidor lo más largo que pueda y tiran todos de él y al fin caen en el suelo» (El sacristán Chinchilla).

En definitiva, las muy lábiles circunstancias de las representaciones teatrales en los corrales de comedias debían de suponer un reto permanente para el entremés, obligado a una adaptación casi instantánea a tales condiciones. Los entremeses del «dramaturgo Olmedo» tienen la cualidad de testimoniar la experiencia del «actor Olmedo", que si en Píramo y Tisbe da muestras de su capacidad para la creación poéti$\mathrm{ca}$, en el resto de sus $"$ sainetes» ${ }^{47}$ las da de su habilidad cómico-teatral, buen conocedor de las tradiciones literarias, de las convenciones del género y de las exigencias del espectáculo, que en algunas ocasiones exigía mayor vuelo en la creación literaria y en otras poner el énfasis en la comicidad derivada del movimiento, de la vista y de los «visajes $»^{48}$.

47 Con este término define el mismo Olmedo a su entremés de Píramo y Tisbe: «Ya que las fábulas logran / más que las historias ganan, / fábula vaya y sainete / de Píramo y Tisbe» (Senabre, 1981, p. 235).

${ }^{47}$ Ver Bergman, 1965, p. 128. 


\section{Bibliografía}

Arcadia de entremeses escritos por los ingenios más clásicos de España: primera parte, Pamplona, Juan Micón, 1691.

Arellano, I., K. Spang y M. C. Pinillos, Apunte sobre la loa sacramental y cortesana: Loas completas de Bances Candamo, Kassel, Reichenberger, 1994.

Asensio, E., Itinerario del entremés desde Lope de Rueda a Quiñones de Benavente. Con cinco entremeses inéditos de D. Francisco de Quevedo, Madrid, Gredos, 1965.

Barrera y Leirado, C. A. de la, Catálogo Bibliográfico y biográfico del teatro antiguo español desde sus orígenes hasta mediados del siglo XVIII (Madrid, 1860), London, Tamesis, 1968.

Bergman, H. E., Luis Quiñones de Benavente y sus entremeses, Madrid, Castalia, 1965.

- (ed.), Ramillete de entremeses y bailes nuevamente recogidos de los antiguos poetas de España. Siglo XVII, Madrid, Castalia, 1984.

Castillo Solórzano, A. de, Donaires del Parnaso, ed. L. López Gutiérrez, Madrid, Universidad Complutense, 2005.

Cervantes, M. de, Entremés del Vizcaíno fingido, en Entremeses, ed. F. Sevilla Arroyo y A. Rey Hazas, Madrid, Alianza Editorial, 1998, pp. 107-130.

Cossío, J. M. de, Fábulas mitológicas en España, Madrid, Istmo, 1998.

Cotarelo y Mori, E., Bibliografía de las controversias sobre la licitud del teatro en España (Madrid, 1904), ed. facsímil J. L. Suárez, Granada, Universidad de Granada, 1997.

— «Noticia de los actores mencionados en las Migajas del Ingenio», en Migajas del Ingenio: colección rarísima de entremeses, bailes y loas, Madrid, ed. E. Cotarelo y Mori, Madrid, 1908, pp. 193-221.

- Colección de entremeses, loas, bailes, jácaras y mojigangas desde fines del siglo XVI a mediados del XVIII (Madrid, 1911), ed. facsímil J. L. Suárez y A. Madroñal, Granada, Universidad de Granada, 2000.

- «Actores famosos del siglo XVII. Sebastián de Prado y su mujer Bernarda Ramírez», Boletín de la Real Academia Española, 3, 1916, pp. 3-38 y 151185.

Díaz de Escovar, N., Algunos datos sobre el antiguo autor de comedias Alonso de Olmedo, Madrid, Millán, 1909.

El teatro menor en España a partir del siglo XVI. Actas del coloquio celebrado en Madrid, Casa de Velázquez, 20-22 de mayo de 1982, Madrid, Centro Superior de Investigaciones Científicas, 1983.

Ferrer Valls, T., Diccionario biográfico de actores del teatro clásico español (DICAT), Kassel, Reichenberger, 2008.

Flores de el Parnaso, cogidas para recreo del entendimiento por los mejores ingenios de España: en loa, entremeses y mojigangas, Zaragoza, Pascual Bueno, 1708. 
Floresta de entremeses y rasgos del ocio, a diferentes asuntos, de bailes y mojigangas, Madrid, Antonio de Zafra, 1691.

García Lorenzo, L. (ed.), Los géneros menores en el teatro español del Siglo de Oro (Jornadas de Almagro 1987), Madrid, Ministerio de Cultura, 1988. García VAldés, C. C., "Nueva presencia del teatro menor», en El redescubrimiento de los clásicos. Actas de las XV Jornadas de Teatro Clásico, ed. F. Pedraza Jiménez, Almagro, Universidad de Castilla-La Mancha, Festival de Almagro, 1993, pp. 103-122.

Genealogía, origen y noticias de los comediantes de España, ed. N. D. Shergold y J. E. Varey, London, Tamesis, 1985.

Góngora, L. de, Romances, ed. A. Carreira, Barcelona, Quaderns Crema, 1998, vol. II.

González Hernández, V., Zaragoza en la vida teatral hispana del siglo XVII, Zaragoza, Institución Fernando el Católico, 1986.

Granja, A. de la, «Hacia una bibliografia general del teatro breve del Siglo de Oro. Primera parte: Estudios I», Criticón, 37, 1987, pp. 227-246.

— «Hacia una bibliografía general del teatro breve del Siglo de Oro. Primera parte: Estudios II», Criticón, 50, 1990, pp. 113-124.

- y M. ${ }^{a}$ L. Lobato, Bibliografía descriptiva del teatro breve español: siglos XV-XX, Madrid / Frankfurt, Iberoamericana / Vervuert, 1999.

Greer, M. R. y J. E. Varey, El teatro palaciego en Madrid: 1586-1707, London, Tamesis, 1997.

Huerta Calvo, J., El teatro breve en la Edad de Oro, Madrid, Ediciones del Laberinto, 2001.

- (dir.), Historia del teatro breve en España, Madrid / Frankfurt, Iberoamericana / Vervuert, 2008.

- E. Peral Vega y H. Urzáiz Tortajada, Teatro español: de la A a la Z, Madrid, Espasa, 2005.

Lambea Castro, M. y L. Josa, «Jácara con variedad de tonos: relaciones entre tonos humanos y música teatral en el siglo XVII», Revista de Musicología, 32, núm. 2, 2009, pp. 397-448.

Loвato, M. L., "Un actor en palacio. Felipe IV escribe sobre Juan Rana», Cuadernos de Historia Moderna, 23, 1999, pp. 79-111.

- (ed.), Loas, entremeses y bailes de Agustín Moreto, Kassel, Reichenberger, 2003, 2 vols.

Madroñal, A., «Estado actual de los estudios sobre teatro breve del Siglo de Oro», Arbor, 177, núm. 699-700, 2004, pp. 455-474.

Muñoz, M., Historia del teatro dramático en España, Madrid, Tesoro, 1953.

Pellicer, C., Tratado histórico sobre el origen y progresos de la comedia y del histrionismo en España, Madrid, Imprenta de la Administración del Real Arbitrio de Beneficencia, 1804, vol. II. 
Pérez Pastor, C., Nuevos datos acerca del histrionismo español en los siglos XVI y XVII. Segunda serie, Bordeaux, Feret, 1914.

Quiñones de Benavente, L., Jocoseria, ed. I. Arellano, J. M. Escudero, A. Madroñal, Madrid / Frankfurt, Iberoamericana / Vervuert, 2001.

Rasgos del ocio en diferentes bailes, entremeses y loas, de diversos autores: segunda parte, Madrid, Domingo García Morrás, 1664.

Rojas Villandrando, A., El viaje entretenido, ed. J. P. Ressot, Madrid, Castalia, 1972.

Romancero general o Colección de romances castellanos anteriores al siglo XVIII, recogidos, ordenados, clasificados y anotados por Don Agustín Durán, Tomo Segundo, Madrid, Rivadeneira, 1851 (BAE, 16).

Rosete, P., Comedia famosa de Píramo y Tisbe, ed. P. Correa Rodríguez, Pamplona, EUNSA, 1977.

SÁnchez Arjona, J., Noticias referentes a los anales del teatro en Sevilla desde Lope de Rueda hasta fines del siglo XVII, Sevilla, Imp. de E. Rasco, 1898.

Senabre, R., "Píramo y Tisbe", entremés inédito de Alonso de Olmedo", Anuario de Estudios Filológicos, 4, 1981, pp. 233-244.

Shergold, N. D. y J. E. Varey, Representaciones palaciegas: 1603-1699. Estudio $y$ documentos, London, Tamesis, 1982.

Simón Palmer, M. del C., Manuscritos dramáticos del Siglo de Oro de la Biblioteca del Instituto del Teatro de Barcelona, Madrid, Centro Superior de Investigaciones Científicas, 1977 (Cuadernos Bibliográficos, XXXIV).

Urzárz Tortajada, H., Catálogo de autores teatrales del siglo XVII, Madrid, Fundación Universitaria Española, 2002.

Varey, J. E. y N. D. Shergold, Comedias en Madrid: 1603-1709: repertorio y estudio bibliográfico, London, Tamesis, 1989.

- Teatros y comedias en Madrid: 1651-1665. Estudio y documentos, London, Tamesis, 1973.

Vélez de Guevara, J., Los celos hacen estrellas, ed. J. E. Varey, N. D. Shergold y J. Sage, London, Tamesis, 1970.

Vergel de entremeses, y conceptos del donaire. Con diferentes bailes, loas y mogigangas. Compuesto por los mejores ingenios destos tiempos, Zaragoza, Diego Dormer, 1675. 